HEROES AND MARTYRS OF QUALITY AND SAFETY

\title{
Bruce Psaty and the risks of calcium channel blockers
}

\section{R A Deyo}

Qual Saf Health Care 2002;11:294-296

O n a fine March day in 1995 Dr Bruce Psaty ascended the podium to present a scientific paper as he had many times before. At a hotel in San Antonio he was speaking before the Epidemiology and Prevention Council of the American Heart Association, a small meeting of academic researchers. Psaty and his colleagues had been studying complications associated with drugs for treating hypertension. The paper seemed innocuous. "It was merely an observational study, so it was unlikely to be seen as important or controversial", he says. But a hostile question and answer session presaged a relentless attack from drug manufacturers. And the apparent controversy piqued the interest of journalists attending the meeting.

Psaty had found that a class of relatively new and expensive drugs-calcium channel blockers-was associated with a higher risk of myocardial infarction than older less expensive drugs. ${ }^{1}$ This was especially true for short acting calcium channel drugs. As soon as he returned home to Seattle Psaty found himself at the center of a maelstrom. Press reports had already appeared, doctors and patients were alarmed, and drug makers were surly.

Psaty's office was inundated with telephone calls and faxes, requiring him to divert staff from research to public relations. The press reports were generally accurate but lacked the caveats and context needed for a clear perspective on the findings. They offered little help for patients who were taking the drugs and wondered what to do. In his interviews Psaty consistently recommended that patients see their own doctors rather than stop taking current medications. He recommended that physicians follow the current guidelines from the Joint National Committee on the Detection, Evaluation and Treatment of High Blood Pressure, which recommended the older cheaper diuretics and beta blockers, unless contraindicated or poorly tolerated. ${ }^{2}$

Furthermore, Psaty was already under attack by the makers of calcium channel blockers. In his office he found a fax to the Dean of the Medical School from Pfizer Corporation, a manufacturer of calcium channel blockers, complaining about Psaty's presentation. Psaty remembers a call from a vice president of Pfizer who "was very angry and wanted to see the data". He also recalls that the Dean of the School of Public Health was contacted by a state legislator to complain about the activities of this University of Washington Professor of Medicine. "I felt vulnerable", says Psaty, "because this was such an unfamiliar and uneven playing field. I was schooled in a scholarly style of debate, not in marketing hyperbole and character attacks". ${ }^{3}$

Psaty fits the stereotypical image of a professor in demeanor and appearance, with his "salt and pepper" beard, balding forehead, large spectacles, and ready smile. In addition to his medical degree and epidemiology training, he has a $\mathrm{PhD}$ in English, so he is a lover of words as well as statistical methods. His intellectual and research interests are broad, and certainly not fixated on the limitations of calcium channel blockers. Fortunately for patients with high blood pressure, though, Psaty has been willing to pursue work on drug safety, sometimes in a chilly atmosphere. Other experts credit Psaty with doing more than anything in the past decade to stimulate rigorous clinical trial research on hypertension.

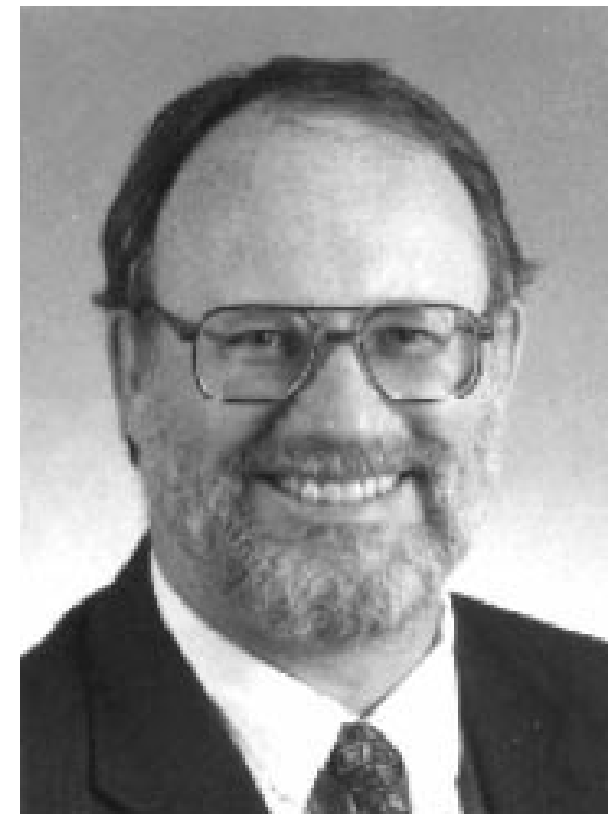

In the ensuing days the Dean of the School of Public Health was called by company officials who suggested that Psaty's work should not be published because it might prove wrong. News stories began to focus on the media's seemingly alarmist handling of the report, which diverted attention from the basic question of drug safety. Psaty wondered if the PR staffs of certain of the manufacturers had helped in this deflection. A blistering "Dear Doctor" letter was distributed nationwide by a prominent expert in high blood pressure, attacking Psaty's work. Only later was it clear that this was sponsored by Bayer, manufacturer of another brand of calcium channel blockers. ${ }^{4}$

According to an article in the Lancet, Bayer was already under investigation in 1995 by the US Department of Health and Human Services for a "kickback program" in which pharmacies received $\$ 35$ for every new prescription of Bayer's brand of calcium channel blocker. In 1994 the company (then known as Miles) had paid a fine of $\$ 605000$ and agreed to drop the scheme.

Psaty received requests from several drug companies that he found intimidating-for documents, tables, manuscripts, and new analyses. Pfizer's attorneys made use of Washington State's Freedom of Information Act to

"... request all records, reports, data, analyses, correspondence, and any other documentation related to the design, conduct, results and conclusions of this study. This includes, but is not limited to, records relating to the following: study design and methodology; study protocol(s); individual data for all study subjects including study and control populations; case report forms; tabulations of study results and data; data sets; statistical calculations, methodologies and analysis; correspondence, meeting minutes, notes and other documentation 
of Dr Psaty and any other university researchers, faculty or staff and of any departmental, staff or other research committees; meeting minutes, reports and other documentation of evaluation by Institutional Review Board and/or other oversight committees or bodies within or outside the University."

Psaty noted that, at the time of this work, roughly $20 \%$ of patients with hypertension were taking calcium channel blockers, so the findings were potentially of major public health significance. The drugs were heavily marketed to physicians and enjoyed a growing market share. They were 15 times more expensive than older alternatives, which were known not only to reduce blood pressure but also to reduce the devastating complications of hypertension such as stroke, myocardial infarction, and heart failure.

Despite the attacks, Psaty's work has withstood the test of time. His report in San Antonio had been a case-control study: an observational design which is more susceptible to certain types of inadvertent bias than randomized trials. ${ }^{1}$ Thus, it was regarded as potentially important but not definitive. Other studies using different research designs have now confirmed Psaty's findings, which appear true for several drugs in this class. $^{6-9}$ Recent meta-analyses combining the results of many randomized trials indicate that calcium channel blockers are less effective at preventing myocardial infarction and heart failure than other antihypertensive agents. ${ }^{7-9}$ The calcium channel blockers are better than placebo for high blood pressure, justifying the manufacturers' claim that they are safe and effective. They just aren't as effective in preventing the complications of hypertension as less expensive alternatives such as low dose diuretics.

This appears to be true despite effective blood pressure lowering by the calcium channel drugs. Thus, Psaty's work helped to raise a more fundamental point: that blood pressure drugs may be very different in their benefits, despite equal success at controlling blood pressure. ${ }^{10}$ This in turn suggests that new drugs should be evaluated not just for their effects on blood pressure, but on its many complications as well.

Much of the controversy focused on short acting preparations of calcium channel blockers, which were associated with the greatest risk in Psaty's initial report. Manufacturers correctly pointed out that some of the short acting drugs had never been approved for the treatment of high blood pressure (they were approved for use in angina). Nonetheless, all the short acting drugs were widely used for this purpose, a fact that was evident in Psaty's data and acknowledged by the FDA. In February 1996, after an Advisory Committee meeting, the FDA issued a letter to makers of calcium channel blockers requiring new labelling that warned against such use. An independent review in 2001 concluded that short acting calcium channel blockers "should be avoided in the routine treatment of hypertension". ${ }^{11}$

Drug makers argued that the evidence did not implicate the longer acting calcium channel blockers. In fact, Pfizer has successfully marketed its long acting calcium channel drug amlodipine (Norvasc) which became the fifth largest selling drug in the world by 2000 with global sales of $\$ 3.3$ billion. $^{12}$ However, recent studies suggest that, compared with other drugs for high blood pressure, even the long acting calcium channel blockers are less effective at preventing heart attacks and congestive heart failure..$^{6-9}$

Additional problems have come to light more recently. Studies published in 2001 found that, compared with other drugs, amlodipine was associated with worse effects on renal function in patients with hypertensive renal disease or diabetes. $^{1314}$ Guidelines prepared by the Joint National Committee continue to recommend the older cheaper drugs as first line therapy for "uncomplicated" high blood pressure, reserving calcium channel blockers only for special situations. ${ }^{15}$

Psaty concludes: "I'm indifferent toward calcium channel blockers. However, I'm a big fan of low dose diuretics which are inexpensive, safe and effective." His advice to patients is: "If you have drug treated high blood pressure and you're not on a low dose diuretic, consider asking your doctor 'why not'?"

Trends in drug use suggest that Psaty's work had at least some impact. A study in British Columbia demonstrated a decline in new prescriptions for calcium channel blockers when the years before and after Psaty's study were compared. Although several other factors were also at play, the researchers attributed part of this change in clinical practice to Psaty's research and the ensuing publicity. ${ }^{16}$

The controversy over Psaty's research also spawned a unique investigation of conflict of interest among medical authors. A group of Canadian doctors identified articles on the controversy that appeared in the medical literature during the 18 months after Psaty's presentation in San Antonio. They contacted the authors of each article to inquire about funding from the makers of calcium channel blockers-including research grants, employment, consulting fees, honoraria, and travel expenses. They found that $96 \%$ of authors who supported the use of calcium channel blockers had financial ties to manufacturers compared with just $44 \%$ of neutral or critical authors. ${ }^{17}$

With the investment of substantial time, good communication with the media, and support from senior collaborators, Psaty has weathered the storm with reputation and sanity intact. On the positive side, the attacks by drug companies raised the visibility of Psaty's research and may paradoxically have helped his career. "In a sense, Pfizer did more to promote the findings of our unwanted study than I could ever have done on my own. And maybe Bayer, too. I don't want to give Pfizer all the credit", he notes. "The whole effort to discredit our work helped to create the calcium channel blocker controversy. Their confrontational methods only served to publicize it widely to physicians and patients alike."

The societal risk is that other investigators may shy away from controversial but important questions after watching investigators like Psaty intimidated by vested interests. For his part, Psaty sees himself as neither crusader nor watchdog. "I don't see myself as a risk taker. I'm just a country scientist," he says. "I delight in doing new stuff and trying to anticipate important questions".

\section{ACKNOWLEDGEMENTS}

Dr Bruce Psaty generously provided information and materials during several conversations. Dr William Applegate and Dr Michael Alderman also provided helpful comments. The Helen Riaboff Whiteley Center at the University of Washington's Friday Harbor Laboratories offered an outstanding environment for research and writing.

Dr R A Deyo, Department of Medicine, Department of Health Services, and Center for Cost and Outcomes Research, University of Washington, Seattle, WA 98195, USA; deyo@u.washington.edu

Supported by a Robert Wood Johnson Investigator Award in Health Policy Research. The conclusions and opinions are those of the autbor and may or may not represent those of the Robert Wood Johnson Foundation.

\section{REFERENCES}

1 Psaty BM, Heckbert SR, Koepsell TD, et al. The risk of myocardial infarction associated with antihypertensive drug therapies. JAMA 1995;274:620-5

2 Joint National Committee on Detection, Evaluation, and Treatment of High Blood Pressure. The Fifth Report of the Joint National Committee on Detection, Evaluation, and Treatment of High Blood Pressure (JNC V). Arch Intern Med 1993:153:154-83.

3 Deyo RA, Psaty BM, Simon G, et al. The messenger under attack: intimidation of researchers by special-interest groups. N Engl J Med 1997;336:1176-80.

4 Stryer DB, Lurie P, Bero LA. Dear Doctor . . . regarding calcium channe blockers. JAMA 1996:275:517.

5 Horton R. Bayer accused of disinformation. Lancet 1995;346:891-2. 
6 Borhani NO, Mercuri M, Borhani PA, et al. Final outcome results of the Multicenter Isradipine Diuretic Atherosclerosis Study (MIDAS). A randomized controlled trial. JAMA 1996;276:785-91.

7 Pahor M, Psaty BM, Alderman MH, et al. Health outcomes associated with calcium antagonists compared with other first-line antihypertensive therapies: a meta-analysis of randomized controlled trials. Lancet 2000;356: 1949-54

8 Neal B, MacMahon S, Chapman N. Effects of ACE inhibitors, calcium antagonists, and other blood-pressure lowering drugs: results of prospectively designed overviews of randomized trials. Blood Pressure Lowering Treatment Trialists Collaboration. Lancet 2000;356: 1955-64.

9 Pahor M, Psaty BM, Alderman MH, et al. Blood-pressure-lowering treatment (letter). Lancet 2001;358:152-3.

10 Furberg CD, Psaty BM, Pahor $M$, et al. Clinical implications of recent findings from the Antihypertensive and Lipid-Lowering treatment to prevent Heart Attack Trial (ALLHAT) and other studies of hypertension. Ann Intern Med 2001;135:1074-8.

11 Kizer JR, Kimmel SE. Epidemiologic review of the calcium channel blocker drugs: an up-to-date perspective on the proposed hazards. Arch Intern Med 2001;161:1145-58.
12 Anon. Trend of the month: global pharmaceutical sales up $11 \%$. Drug Benefit Trends 2001;13:8.

13 Agodoa LY, Appel L, Bakris GL, et al. Effect of ramipril vs amlodipine on renal outcomes in hypertensive nephrosclerosis: a randomized controlled trial. JAMA 2001;285:2719-28.

14 Lewis EJ, Hunsicker LG, Clarke WR, et al. Renoprotective effect of angiotensin-receptor antagonist irbesartan in patients with nephropathy due to type 2 diabetes. N Engl J Med 2001;345:851-60.

15 Joint National Committee on Prevention Detection, Evaluation and Treatment of High Blood Pressure. The Sixth Report of the Joint National Committee on Prevention, Detection, Evaluation, and Treatment of High Blood Pressure. Arch Intern Med 1997;157:2413-46.

16 Maclure M, Dormuth C, Naumann T, et al. Influences of educational interventions and adverse news about calcium-channel blockers on first line prescribing of antihypertensive drugs to elderly people in British Columbia. Lancet 1998;352:943-8.

17 Stelfox HT, Chua G, O'Rourke K, et al. Conflict of interest in the debate over calcium-channel antagonists. N Engl J Med 1998;338:101-6. 